\title{
THERMAL DECOMPOSITION REACTION IN ETHANOL SOLUTION OF DEUTERATED ACETONE CYCLIC DIPEROXIDE AND ACETONE DIPEROXIDE. SECONDARY INVERSE ISOTOPIC EFFECT
}

\author{
Karina Nesprias $^{\mathrm{a}, \mathrm{b}, *}$, Gladys Eyler ${ }^{\mathrm{b}}$, Adriana Cañizo ${ }^{\dagger, \mathrm{b}}$ and Gastón Barreto ${ }^{\mathrm{b}}$ \\ a'Departamento de Ciencias Básicas, Facultad de Agronomía, Universidad Nacional del Centro de la Provincia de Buenos Aires, \\ Av. República de Italia 780, B7300, Azul, Buenos Aires, Argentina \\ 'Facultad de Ingeniería, CIFICEN-UNCPBA - CICPBA - CONICET. Avda. del Valle 5737, B7400JWI, Olavarría, Buenos Aires, \\ Argentina
}

Recebido em 07/09/2016; aceito em 04/01/2017; publicado na web em 28/03/2017

\begin{abstract}
The characterization by mass spectrometry and the kinetic study of the thermal decomposition reaction of deuterated acetone diperoxide (dACDP) was studied in ethanol in the $140-165^{\circ} \mathrm{C}$ temperature range. The comparison with the non deuterated species (ACDP) was also made. The kinetic behavior observed for both compounds follows a pseudo first order kinetic law up to at least 86 $\%$ peroxide conversions. It could be observed that under the established experimental conditions, the dACDP decomposes $c a .1 .2$ times faster than the ACDP. The activation parameters were calculated for both peroxides and allowed to postulate a single process initial step, the unimolecular thermal decomposition through the $\mathrm{O}-\mathrm{O}$ bond cleavage to form an intermediate biradical. The products of the acetone derived peroxides thermal decomposition support a radical-based decomposition mechanism. The changes in kinetic parameters between $\mathrm{AACDP}$ and ACDP were justified attending to differences in ring substituents sizes. A secondary inverse kinetic isotope effect is observed $\left(\mathrm{k}_{\mathrm{H}} / \mathrm{k}_{\mathrm{D}}<1\right)$.
\end{abstract}

Keywords: isotopic secondary inverse effect; acetone diperoxide; deuterated acetone diperoxide; thermolysis.

\section{INTRODUCTION}

During the past decade, interest on the chemistry of cyclic organic peroxides has emerged since such compounds are widely found in nature and often have promising pharmacological properties and are used at industrial level. Also, a great number of studies have been carried out concerning the examination of the behavior of cyclic organic peroxide to know the kinetics, the substituent effect and the mechanism of their decomposition reactions in different solvents. Additionally, different results related with new synthetic methods or alternative techniques that involve greater yields of peroxide compound in a shorter preparation time were reported. ${ }^{1-5}$

Peroxides are shock sensitive and their overall decompositions are exothermic so that special handling precautions must be taken. Depending on the molecular group linked on the peroxide ring, their decomposition may be explosive in different degrees. Most peroxides, such as the commonly used dibenzoyl peroxide or di-t-butyl peroxide, contain too much carbon to be true explosives; but they have been rated as having TNT equivalence of $25 \%$ and $30 \%$, respectively. ${ }^{6}$

In this sense, triacetone triperoxide (3,3,6,6,9,9-hexamethyl$-1,2,4,5,7,8$-hexaoxacyclonane, TATP) is one of the most sensitive explosives known with a power close to that of TNT (a $10 \mathrm{~g}$ sample gave $250 \mathrm{~cm}^{3}$ expansions in the Trauzl test as compared to $300 \mathrm{~cm}^{3}$ for TNT), a property that allows its employment as both primary explosive and main charge. ${ }^{4,5}$

Primary explosives form a group of compounds that are considered to be highly sensitive to some mechanical stimuli such as impact, friction, stab, heat, static electricity, flame, etc. Sensitivity of explosives to friction is one of the fundamental parameters to be considered, ${ }^{5}$ attending to safety manipulation of this type of compounds. Some of the organic cyclic peroxides employed in this research belong to this category.

\footnotetext{
*e-mail: knespria@faa.unicen.edu.ar
}

On the other hand, organic peroxides have industrial applications; they are used as active components of cosmetics and pharmaceuticals as hardener and curing agents for plastics such as unsaturated polyester and fiber glass resins and they have biochemical effects because their free radicals generate severe metabolic acidosis, hemolysis, gastric necrosis, and perforation of the stomach ${ }^{1}$.

Organic peroxides are usually used as free radical initiators in the free radical polymerization of most commercial vinyl polymers such as polystyrene, polymethylmethacrylate, polyethylene and poly (vinyl chloride) industrially produced. Cyclic organic di- and triperoxides decompose thermally by homolytic cleavage of the $\mathrm{O}-\mathrm{O}$ bond to give an intermediate biradical, which in turn initiates the polymerization of vinyl monomers. The biradical species is incorporated into the growing polymer structure yielding polymeric products containing peroxide groups that decompose later during the polymerization process. This behavior allows to obtain polymers with high molecular weights, in a lower polymerization time and with improved mechanical properties than those obtained with mono- or bifunctional classic initiators. ${ }^{2,7}$

In previous works, it was demonstrated that an important substituent effect is operative on kinetic and activation parameters of the thermal decomposition reaction of substituted tetraoxacyclohexanes derived from acetone, pinacolone, 4-heptanone, benzophenone, dibenzylketone, cyclohexanone or acetophenone in different organic solvents. , $^{3,11}$

It has been widely published that the rate-determining step of the thermal decomposition reaction of the cyclic peroxides is the biradical intermediate formation (Eq. 1). ${ }^{9,12-16}$

It is very improbable that the biradical-activated complex would be solvated to the same extent as the starting material since differences in the electronic configuration, and therefore polarizability, should exist. The differential solvation of starting material and biradical-activated complex should lead to a difference in the reaction rate and subsequently in the activation parameter (e.g., energy of activation). The solvent cavity requirement for the activated complex of a radical 


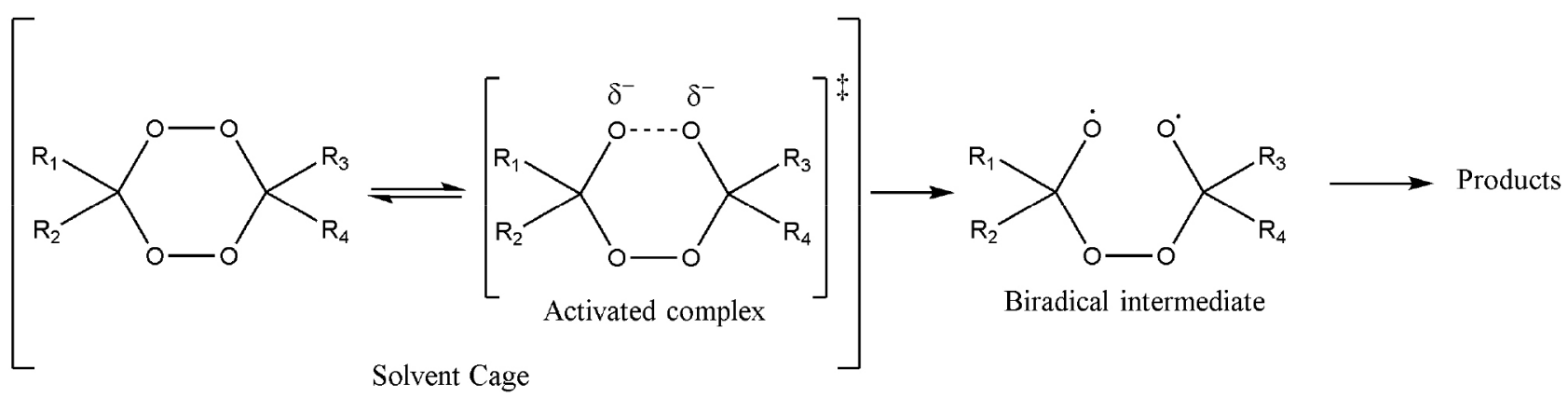

reaction should certainly be different (size and shape) from that of the reactant. Changes in the reaction solvent or in the cycle peroxide substituents generate changes in the reaction rates.

Recently, the existence of isotopic effect on the experimental infrared has been reported and Raman data were obtained with a tetrasubstituted-1,2,4,5-tetraoxacyclohexane synthesized starting with deuterated acetone (deuterated acetone cyclic diperoxide, dACDP) in comparison with that compound obtained from acetone (acetone cyclic diperoxide, ACDP) (Figure 1). ${ }^{10}$

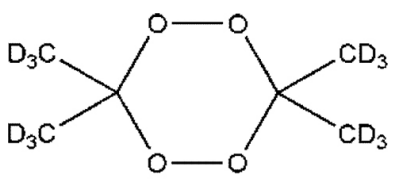

dACDP

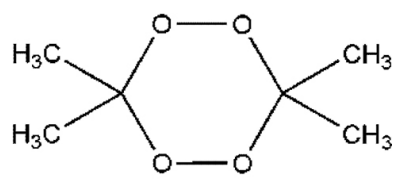

ACDP
Figure 1. Structures of cyclic diperoxides

In some deuterated molecules, the existence of a kinetic isotope effect (KIE) ${ }^{17}$ can be observed. This effect refers to the change in the rate of a chemical reaction when the atoms in the reactant are substituted with one of its isotopes. The KIE is a mechanistic phenomenon where isotopically substituted molecules react at different rates and it is expressed as the ratio of the rate constants $\left(\mathrm{k}_{\text {atom }} / \mathrm{k}_{\text {isotope }}\right)$. The resulting KIE may be normal or inverse depending on the specific contributions of the respective vibrations. In general, larger force constants in the transition state are expected to yield an inverse kinetic isotope effect when stretching vibrational contributions dominate the kinetic isotope effect.

On the other hand, a secondary KIE is observed since the bond to isotopically substituted atom in the reactant is not broken in the rate-determining step of a reaction. In this case, the rate constant values are associated with the cleavage of an $\mathrm{O}-\mathrm{O}$ bond leading to a biradical (Eq. 1). The magnitudes of such secondary isotope effects at the $\alpha$-carbon are largely determined by the $\mathrm{C} \alpha-\mathrm{H}$ (D) vibrations. ${ }^{17-20}$

The present work aims to complete the study of differentiation of both peroxides by evaluating the mass spectrum and investigating their thermal decomposition, isotopic and substituent effects in ethanol solution, where the mass of the substituent only changes due to the incorporation of deuterium but the total number of carbon atoms is maintained constant.

\section{EXPERIMENTAL}

\section{Preparation and characterization of AACDP and ACDP}

Di functional cyclic organic peroxides (Figure 1) employed in this work were prepared by methods described in the literature. ${ }^{10,12}$ dACDP was characterized by Raman and FTIR Spectroscopy and ACDP purity was checked by CG and IR analysis.

The mass spectrum of each cyclic diperoxide was obtained by
Gas Chromatography coupled to Mass Spectrometry (GC-MS) using a Rtx-5MS capillary column (5\% diphenyl - $95 \%$ dimethyl polysiloxane, $30 \mathrm{~m}, 0.25 \mathrm{~mm}$ I.D., $0.25 \mu \mathrm{m}$ film thickness), installed in a Thermo Quest Trace 2000 CG model gas chromatograph with helium as carrier gas $\left(1 \mathrm{~mL} \mathrm{~min}^{-1}\right)$ and injection port at $150{ }^{\circ} \mathrm{C}$ in split mode (split ratio: 1:33, split flow: $33 \mathrm{~mL} \mathrm{~min}^{-1}$ ). The detection was carried out with a Finnigan Polaris Ion trap MS with transfer line at $210^{\circ} \mathrm{C}$ and ion source at $200{ }^{\circ} \mathrm{C}$. The oven temperature was maintained at $50{ }^{\circ} \mathrm{C}$ for $4 \mathrm{~min}$, then programmed at $10^{\circ} \mathrm{C} \mathrm{min}^{-1}$ to $200{ }^{\circ} \mathrm{C}$ for $5 \mathrm{~min}$.

The short time of residence of ACDP and AACDP in the injector at $150{ }^{\circ} \mathrm{C}$ made decomposition negligible. Additionally, the absence of decomposition products in the initial solutions for both peroxides was confirmed by GC analysis.

Warning - The preparation and handling of cyclic organic peroxides for the objectives of this work are dangerous operations that require standard safety precautions for handling primary explosives. These compounds are sensitive to impact, friction, electric discharge, shock and flame.

Organic peroxides in solid state tend to react with metals so nonmetallic spatulas should be used. Glass containers, stainless steel, polyethylene or Teflon are suggested for handling and storage; steel, copper alloys, rubber and lead should not be used. Organic peroxides should not be mixed directly with materials containing heavy metal ions such as iron, cobalt or manganese, since these promote the decomposition of peroxides. In case of fire, an explosion can be anticipated. A foam extinguisher can be used for small fires.

CAUTION: Observe the normal safety precautions for handling peroxidic materials. ${ }^{21}$ It is generally known that peroxides can be detonated by shock.

The risks of friction and heat can be controlled by synthesizing only small amounts of ACPD and AACDP, eliminating heat sources, the use of coated boards Teflon spatulas glass and storing small amounts of samples in the refrigerator or as solutions until required. ${ }^{22}$

\section{Solvents}

The solvent employed in the reaction was purified with the appropriate techniques ${ }^{23}$ and its purity was checked by GC analysis.

Ethanol used as solvent was distilled from ethylenediaminetetraacetic acid disodium salt to remove traces of metallic ions. Sublimed naphthalene was employed as an internal standard in quantitative GC determinations.

\section{Kinetic method}

Pyrex glass tubes $(7 \mathrm{~cm}$ long x $6 \mathrm{~mm} \mathrm{o.} \mathrm{d.)} \mathrm{half} \mathrm{filled} \mathrm{with} \mathrm{the}$ appropriate cyclic diperoxide in ethanol solution were thoroughly degassed under vacuum at $-196^{\circ} \mathrm{C}$ and then sealed with a flame torch with natural gas and oxygen. To perform the runs, the ampoules were submerged in a thermostatic silicone oil bath (PolyScience model 9001) stabilized at a selected temperature $\left( \pm 0.1^{\circ} \mathrm{C}\right)$ and extracted 
after predetermined times. The peroxide decomposition reaction was stopped by cooling the ampoules in an ice-water bath $\left(0^{\circ} \mathrm{C}\right)$.

The peroxide remaining in the solution was determined by GC (internal standard method) employing a DB-5 capillary column (5\% biphenyl - 95\% dimethyl polysiloxane, $30 \mathrm{~m}$ x $0.32 \mathrm{~mm}$ i.d., 0.25 $\mathrm{mm}$ film thickness) installed in a Konik-2000C gas chromatograph, with nitrogen as carrier gas and flame ionization detection $\left(250^{\circ} \mathrm{C}\right)$. The injection port was fixed at $150{ }^{\circ} \mathrm{C}$ in split mode.

The pseudo first order rate constants $\left(\mathrm{k}_{\text {exp }}\right)$ were calculated from the slope of the linear regression obtained by a least mean square analysis of the experimental data by plotting the values of $\ln$ (peroxide concentration) vs reaction times.

The activation parameters were calculated using the Eyring equation (Eq. 2):

$$
\ln \left(\frac{k_{\exp }}{T}\right)=-\frac{\Delta H^{\ddagger}}{R T}+\frac{\Delta S^{\ddagger}}{R}+\ln \left(\frac{R}{N_{A} h}\right)
$$

where $\Delta \mathrm{H}^{\ddagger}$ is the activation enthalpy, $\Delta \mathrm{S}^{\ddagger}$ activation entropy, $\mathrm{T}$ is the temperature at which each constant $\left(\mathrm{k}_{\text {exp }}\right)$ was determined, $\mathrm{R}$ is the general gas constant, $\mathrm{N}_{\mathrm{A}}$ is Avogadro's number $\left(6.02 \times 10^{23}\right.$ molecules $\left.\mathrm{mol}^{-1}\right)$ and $\mathrm{h}$ is Planck's constant $\left(6.63 \times 10^{34} \mathrm{~J} \mathrm{~s}\right)$.

The experimental errors correspond to the standard deviations derived from a treatment of the kinetic data by the method of minimum squares. ${ }^{24}$

\section{RESULTS AND DISCUSSION}

\section{ACDP and dACDP characterization}

As it can be seen in Figure 2 (a), the spectrum of ACDP shows a small quantity of peaks and the molecular ion is not present $(\mathrm{m} /$ $\mathrm{z}=148$ ), demonstrating a significant instability of the peroxide derived molecular ion in the environmental conditions of analytical instrumentation. When the synthesis of peroxide is carried out under the same experimental conditions but using deuterated acetone as starting reagent, the mass spectrum (Figure 2 (b)) presents some shifts in peaks.

The main fragment ions $(\mathrm{m} / \mathrm{z}=59,58$ and 43$)$ can be justified attending to the fragmentation mechanism proposed in Scheme 2 where the fragmentation would seem to be carried out through alpha type ruptures initiated at radical site. The peak with $\mathrm{m} / \mathrm{z}=59$ can be justified assuming a rearrangement of hydrogen and a subsequent alpha rupture. The shifts that appear in Figure 2 (b) can be justified proposing the same fragmentation mechanism (CG-MS analysis) as in the case of ACDP but replacing hydrogen by deuterium. It means that the fragmentation mechanism proposed could be the same considering the presence of deuterium instead of hydrogen in the structures (Figure 3).

The dACDP was characterized by another author by Raman and FTIR Spectroscopy. ${ }^{10}$ In this work, the mass spectrums of the totally
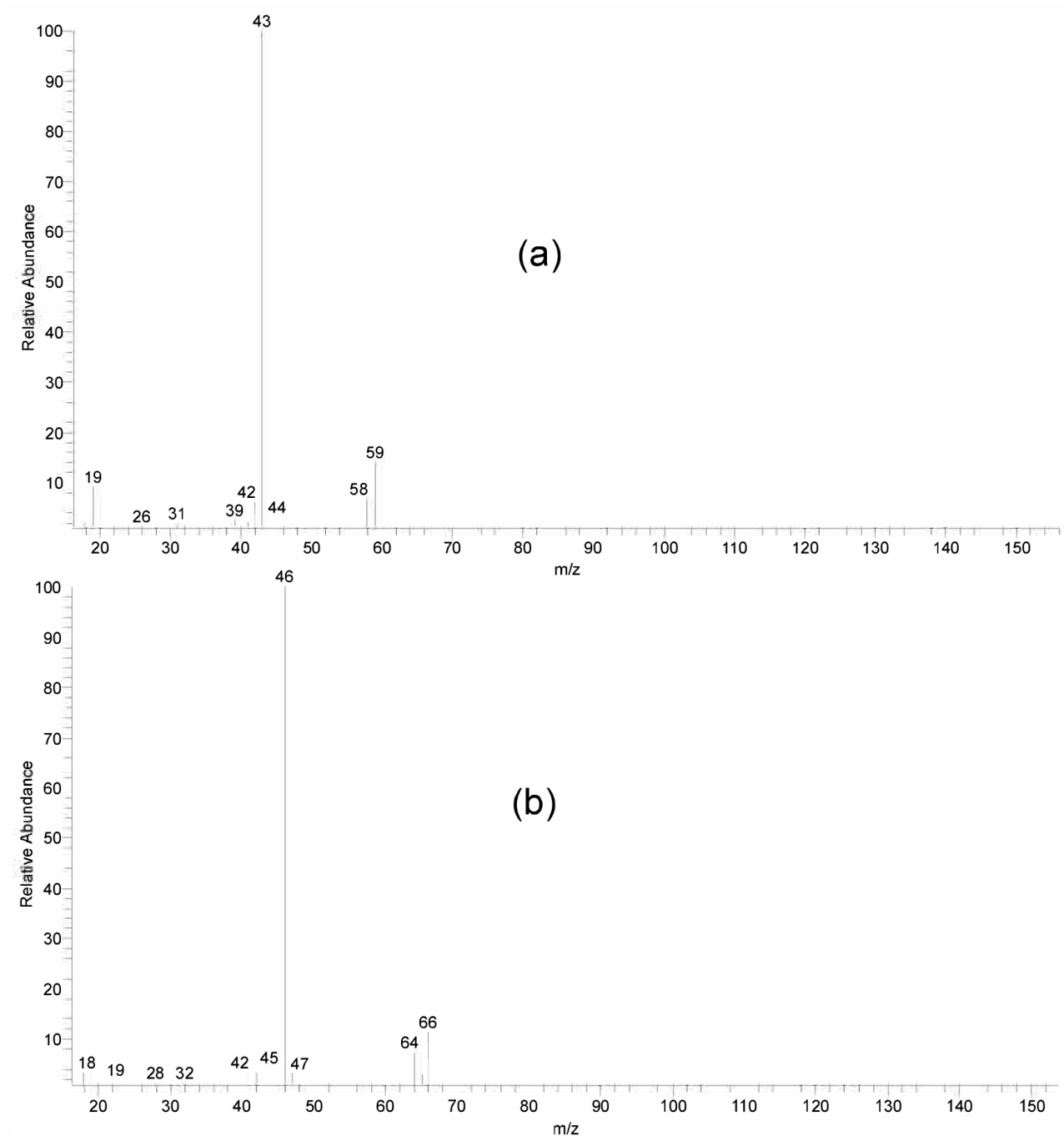

(a)

$\mathrm{m} / \mathrm{z}$

Figure 2. Mass spectrum of acetone derived diperoxides: (a) ACDP and (b) dACDP 


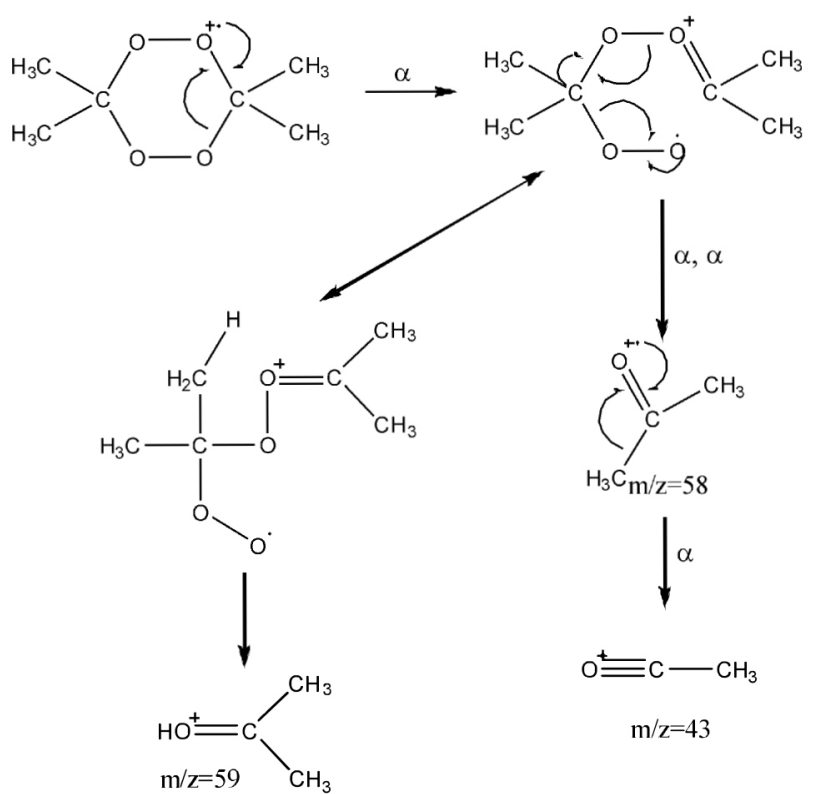

(a)

Figure 3. Proposed mechanism for (a) ACDP and (b) dACDP fragmentations

deuterated substance were obtained in order to complement the existing data and to confirm the assignment of bands.

\section{Kinetic analysis}

The thermal decomposition reactions of dACDP and ACDP were studied in ethanol solvent at initial concentrations of $c a$. $10^{-2} \mathrm{~mol} \mathrm{~L}^{-1}$ and at temperatures between 140 and $165^{\circ} \mathrm{C}$ (Table 1). The kinetic behavior observed in both cases follows a pseudo first order kinetic law up to at least $86 \%$ peroxide conversion.

The initial peroxide concentration is relatively low to avoid effects of induced second order decomposition reactions that would accelerate the thermal decomposition of the peroxides at higher conversions.

Table 1. Pseudo-First-Order rate constant values for the thermal decomposition reaction of ACDP and AACDP in ethanol

\begin{tabular}{lccc}
\hline Peroxide & $\begin{array}{c}\text { Temperature } \\
\left({ }^{\circ} \mathbf{C}\right)\end{array}$ & $\begin{array}{c}\mathbf{k}_{\text {exp }} \mathbf{x} \mathbf{1 0}^{\mathbf{6}} \\
\left(\mathbf{s}^{-1}\right)\end{array}$ & $\mathbf{r}^{\mathbf{2}}$ \\
\hline \multirow{3}{*}{ ACDP } & 140.0 & 8.6 & 0.998 \\
& 150.0 & 15.8 & 0.996 \\
& 165.0 & 59.1 & 0.999 \\
\hline \multirow{3}{*}{ dACDP } & 140.0 & 10.1 & 0.987 \\
& 150.0 & 19.1 & 0.989 \\
& 165.0 & 76.2 & 0.998 \\
\hline
\end{tabular}

The reactivity of both compounds was compared at different temperatures (Table 1), observing that in all cases dACDP decomposes ca. 1.2 times faster than ACDP.

In general, the high decomposition reaction rate of some organic cyclic peroxides is probably associated with the large size of the substituents. Thus, once the ring is opened through the initial $\mathrm{O}-\mathrm{O}$ bond (Eq. 1), the intermediate species formed would adopt highly stable conformations within a new reorganized solvent cage that prevent the recyclization process from occurring. Consequently, the reaction progresses with the decomposition of the initial biradical to form the detected reaction products with high values of $k_{\text {exp }}$.

The van der Waals volumes for both cyclic organic peroxides were

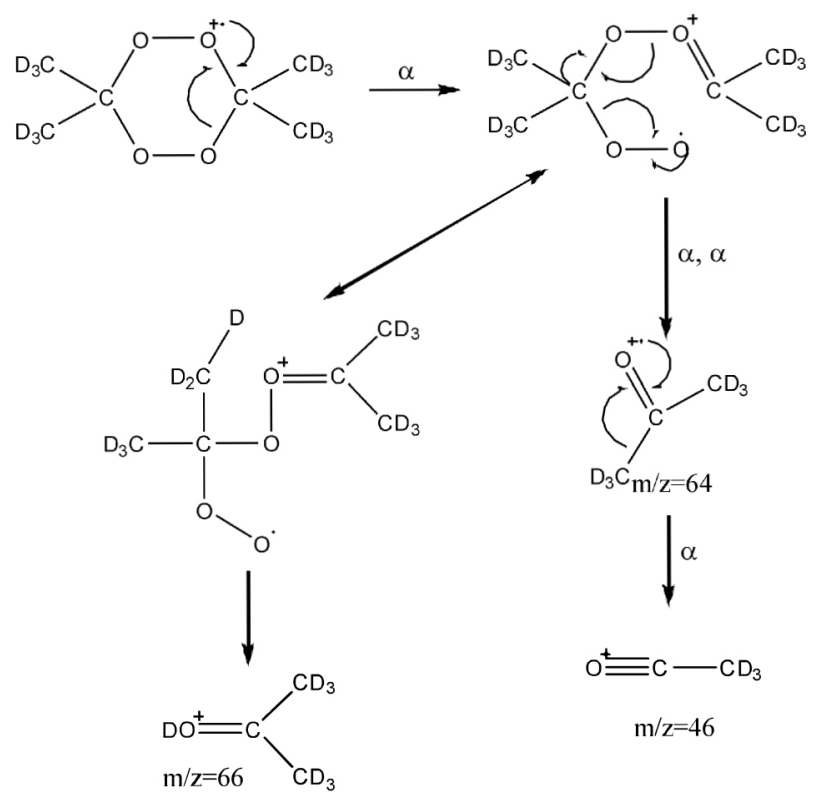

(b)

calculated according to the expression deduced by other authors ${ }^{25}$ (Eq. 3) using the data in Table 2:

$V_{\text {vdW }}\left(\AA^{3}\right.$. Molecule $\left.{ }^{-1}\right)=\Sigma$ all atom contributions $-5.92 N_{\mathrm{B}}-$ $14.7 \mathrm{R}_{\mathrm{A}}-3.8 R_{\mathrm{NR}}$

when: $\mathrm{N}_{\mathrm{B}}$ : bond contribution; $\mathrm{R}_{\mathrm{A}}$ : number of aromatic ring; $\mathrm{R}_{\mathrm{NR}}$ : number of non aromatic ring

Table 2. Bondi radii of atoms and their volumes

\begin{tabular}{ccc}
\hline Atom & $\mathbf{R}_{\text {BONDI }}\left(\AA^{\mathbf{A}}\right)$ & $\mathbf{V}_{\text {vdW }}\left(\AA^{3}\right.$ atom $\left.^{-1}\right)$ \\
\hline $\mathrm{H}$ & 1.2 & 7.24 \\
$\mathrm{D}$ & 1.4 & 11.49 \\
$\mathrm{O}$ & 1.52 & 14.71 \\
$\mathrm{C}$ & 1.7 & 20.58 \\
\hline
\end{tabular}

ACDP has a smaller volume than $\operatorname{dACDP}\left(135.9 \AA^{3}\right.$ molecule ${ }^{-1}$ and $186.2 \AA^{3}$ molecule ${ }^{-1}$ respectively), and shows the lowest reactivity in ethanol solution at all temperature ranges. ACDP with minor size decomposes at the lowest rates in comparison with dACDP with deuterated substituents, probably because it can be confined in a compact solvent cage where the recyclization reaction is more probable.

It is likely that the solvent molecules are able to interact more strongly with a small acetone peroxide molecule generating a close packed system. Thus, this subsequent decomposition of the critical state of the reaction (formation of a biradical in solution, Eq. 1) would be confined to a small 'solvent cage' with strong interaction energy, which would delay species to yield the corresponding reaction products.

The increment in masses of the deuterated substituents on $\mathrm{C} 3$ and C6 of the tetraoxacyclohexane ring is probably responsible for the displacement of the reaction to the products formation with a higher $k_{\exp }$ value for dACDP than for ACDP (Table 1).

In previous works, it was demonstrated that the presence of voluminous substituents on the cycle accelerates the reaction; i.e. cyclic diperoxide derived from 3, 3-dimethyl-2-butanone (pinacolone) 
decomposes in different solvents at higher rates than ACDP. ${ }^{2,8,11}$

The presence of deuterium in ACDP and the kinetic behavior shown allow postulating a KIE. The relation between kinetic constants that are greater than $1\left(\mathrm{k}_{\mathrm{H}} / \mathrm{k}_{\mathrm{D}}>1\right)$ is referred to as normal KIE, while those that are less than one is referred to as inverse $\operatorname{KIE}\left(\mathrm{k}_{\mathrm{H}} / \mathrm{k}_{\mathrm{D}}<1\right)$. In this case the latter effect occurs (Table 3).

Table 3. Inverse kinetic isotope effects (IKIE), for acetone diperoxide and deuterated acetone diperoxide

\begin{tabular}{cc}
\hline $\begin{array}{c}\text { Temperature } \\
\left({ }^{\circ} \mathbf{C}\right)\end{array}$ & $\begin{array}{c}\mathbf{k}_{\mathrm{H}} / \mathbf{k}_{\mathbf{D}} \\
\left(\mathbf{s}^{-1}\right)\end{array}$ \\
\hline 140.0 & 0.85 \\
150.0 & 0.83 \\
165.0 & 0.76 \\
\hline
\end{tabular}

In the whole range of temperatures studied for the thermal decomposition of both peroxides, it is observed that dACDP has a higher reaction rate than ACDP (Table 1). Thus, the relation between the rate constants of both compounds is less than $1\left(\mathrm{k}_{\mathrm{H}} / \mathrm{k}_{\mathrm{D}}\right)$, so that the existence of an inverse isotope effect can be postulated. In this case the reaction is initiated by the rupture of the O-O bond to form the intermediate biradical and the rupture of the $\mathrm{C}$-D bond does not occur in the rate-determining step of reaction. This is called the secondary isotopic effect. A computational and dynamical study is necessary to completely understand these results.

In general, the reactivity of the substituted cyclic peroxides is higher in protic hydrogen bonding donor solvents such as 2-propanol, methanol, acetic acid and ethanol ${ }^{16,26,27}$. In aromatic or aliphatic solvents with low polarity (toluene, benzene and $n$-octane), the rate constant values are smaller ${ }^{2,8,9}$. The trend demonstrates that an increase in the solvent polarity is accompanied by an increase in the reaction rate as a consequence of a reaction mechanism involving a more dipolar-activated complex than the diperoxide initial molecule, which could be stabilized by polar solvents. In this sense, the rate decomposition constant of ACDP in ethanol (Table 1) is 77.3 percent higher than in $n$-octane at the same temperature ${ }^{9}$. On the other hand, substituent effects on the rate constant and on the activation parameters of cyclic organic peroxides have been analyzed and discussed in previous works. ${ }^{2,10}$

The corresponding rate constant values of ACDP thermal decomposition reaction are shown in Table 4, where some data obtained in a previous work were included. The alcohols in Table 4 may be classified as primary and secondary, and in that sense the results have shown that the reaction is accelerated in the secondary ones, probably because 2-propanol interacts more with the ACDP molecule favoring the biradical formation. The same was observed for acetone cyclic triperoxide ACTP. ${ }^{27}$

The $\mathrm{k}_{\exp }$ values of the ACDP thermolysis at $150^{\circ} \mathrm{C}$ (Table 4) are higher in 2-propanol, and secondary alcohol, than in the primary ones (ethanol, 1-propanol and 1-octanol), probably because the former interacts more with the ACDP molecule favoring the biradical formation (Eq. 1). Moreover, the primary alcohol interacts only through
Table 4. Pseudo-first order rate constant values of ACDP thermolysis (ca. $0.02 \mathrm{~mol} \mathrm{~L}^{-1}$ initial concentration in alcohols with $\mathrm{Na}_{2}$ - EDTA treatment) at $423 \mathrm{~K}$

\begin{tabular}{lccc}
\hline Peroxide & Solvent & $\mathrm{k}_{\text {exp }} 10^{6}, \mathrm{~s}^{-1}$ & Ref. \\
\hline \multirow{3}{*}{ ACDP } & Ethanol & 15.8 & This work \\
& 2-propanol & 37.4 & 13 \\
& Methanol & 22.2 & 28 \\
& 1-octanol & 27.1 & 28 \\
dACDP & 1-propanol & 26.7 & 14 \\
\hline \multirow{2}{*}{ ACTP } & Ethanol & 19.1 & This work \\
& Ethanol & 24.0 & 27 \\
\hline
\end{tabular}

anterpolated value.

the hydrogen atom in the $\mathrm{OH}$ group with the $\mathrm{O}-\mathrm{O}$ bond.

The activation enthalpy and entropy values corresponding to the unimolecular thermal decomposition reaction of ACDP and dACDP agree with already reported data for analogous cyclic organic peroxides, in similar solvent..$^{9,11,16,26}$ The linearity of the $\ln \mathrm{k}_{\exp } \mathrm{T}^{-1} v s . \mathrm{T}^{-1}$ plot in a relatively large temperature interval $\left(140\right.$ to $\left.165^{\circ} \mathrm{C}\right)$ supports that the calculated activation parameter values for the ACDP and dACDP reaction in ethanol solvent belong to a single process, the unimolecular thermal decomposition through the $\mathrm{O}-\mathrm{O}$ bond cleavage to form the intermediate biradical, as the initial bond-breaking step (Eq. 1).

The $\Delta \mathrm{G}^{\ddagger}$ values obtained for both systems are practically the same, but the $\Delta \mathrm{H}^{\ddagger}$ and $\Delta \mathrm{S}^{\ddagger}$ values are different; in this case a compensation effect can be considered when a change in the activation enthalpy is accompanied by a change in the same sense in the corresponding activation entropy (Table 5). As a consequence of this compensation effect, $\Delta \mathrm{G}^{\ddagger}$ values remained nearly constant $\left(\Delta \Delta \mathrm{G}^{\ddagger}=0.7 \mathrm{~kJ} \mathrm{~mol}^{-1}\right)$. Under the experimental conditions employed in the present work, it is possible to assume that both peroxides decompose by the same initial reaction mechanism with an evident substituent effect related to the presence of deuterium.

The activation parameters for the thermolysis reaction of ACDP and dACDP in different aliphatic alcohols are shown in Table 5. The activation parameters of the thermal decomposition reaction of ACDP in ethanol solution are similar to those corresponding to the obtained for the same peroxide in 1-octanol solution. The activation entropies values of ACDP are negative, and they can be explained by the interaction by hydrogen bonding link solute - solvent (primary alcohols) or the formation of cyclic species between the hydrogen atoms of the $\mathrm{OH}$ group and the $\mathrm{H}$ linked at $\mathrm{C} 2$, with the $\mathrm{O}-\mathrm{O}$ bond in the peroxide molecule (secondary alcohol). The low values of $\Delta \mathrm{S}^{\ddagger}$ can be associated with a decrease in the rotational and translational degrees of freedom of peroxides molecules, which generates a rigid state as a consequence of higher interactions between peroxide and alcohol molecules. As a result of this behavior, the scission of the peroxide bond is accelerated and a higher value of rate constant is observed.

Table 5. Activation parameter for the thermal decomposition reaction of dACDP and ACDP in different alcohols

\begin{tabular}{|c|c|c|c|c|c|c|}
\hline Cyclic Peroxide & $\begin{array}{c}\Delta \mathbf{T} \\
{\left[{ }^{\circ} \mathbf{C}\right]} \\
\end{array}$ & Solvent & $\begin{array}{c}\Delta \mathbf{H}^{\ddagger} \\
{\left[\mathbf{k J ~ m o l}^{-1}\right]}\end{array}$ & $\begin{array}{c}\Delta \mathbf{S}^{\ddagger} \\
{\left[\mathrm{J} \mathrm{mol}^{-1} \mathbf{K}^{-1}\right]}\end{array}$ & $\begin{array}{c}\Delta \mathbf{G}^{\ddagger} \\
{\left[\mathrm{kJ} \mathrm{mol}^{-1}\right]}\end{array}$ & ref \\
\hline ACDP & 25 & Ethanol & $112.14 \pm 2.10$ & $-73.51 \pm 4.86$ & $143.40 \pm 2.10$ & This work \\
\hline ACDP & 36 & 1-octanol & $109.33 \pm 1.25$ & $-76.28 \pm 2.51$ & $140.83 \pm 1.25$ & 28 \\
\hline ACDP & 76 & 2-propanol & $85.12 \pm 1.59$ & $-124.30 \pm 3.91$ & $136.44 \pm 1.59$ & 27 \\
\hline dACDP & 25 & Ethanol & $117.53 \pm 1.47$ & $-59.15 \pm 3.47$ & $142.70 \pm 1.47$ & This work \\
\hline
\end{tabular}




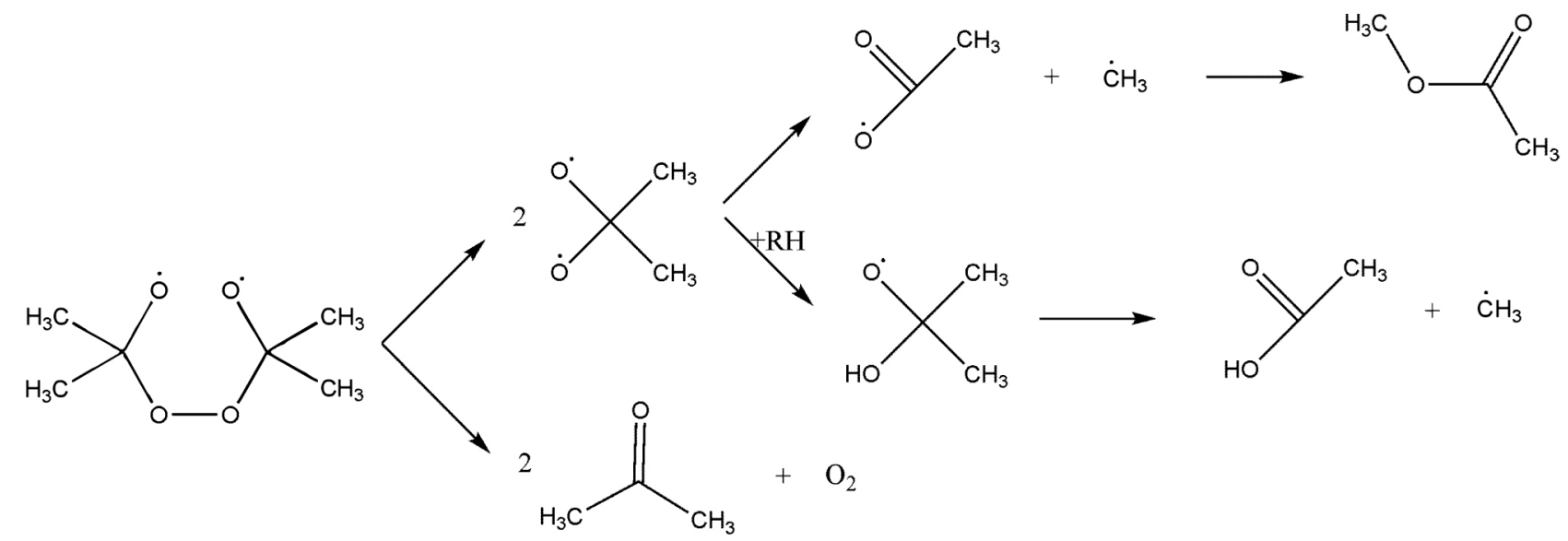

Figure 4. Reaction mechanism for the decomposition of the initial biradical derived from ACDP

\section{Reaction products}

The biradical species (Eq. 1) can re-form the diperoxide molecule or undergo either $\mathrm{C}-\mathrm{O}$ bond cleavage to give 2-propanone, or O-O bond cleavage to yield a new biradical species, which can undergo $\mathrm{C}-\mathrm{C}$ bond cleavage to give methyl and ethanoate radicals. Ethanoate radicals can abstract a hydrogen atom from solvent to produce ethanoic acid or recombine with the methyl radical to form methylethanoate. A radical-radical coupling reaction between two methyl radicals may explain the detection of ethane as a product.

The presence of 2-propanone as one of the decomposition products of ACDP was recognized though the interaction of mass spectrum and also by comparison of its retention time with that obtained by injecting a standard sample of this compound in the gas chromatograph with FID detection. Other products were identified qualitatively by interpretation of their mass spectrum (acetic acid, methylethanoate) (Figure 4).

\section{CONCLUSION}

Cyclic organic diperoxides derived from acetone and deuterated acetone (ACDP and dACDP) follow a pseudo-first order kinetic law during their thermal decomposition reaction between 140 to $165^{\circ} \mathrm{C}$. The first step of the reaction mechanism is the formation of a biradical species which later decomposes to give some reaction products (2-propanone, acetic acid and methyletanoate). These products support the postulation of the radical step mechanism. The reactivity of both compounds was compared at different temperatures. The temperature effect on the rate constant values demonstrated that the deuterated acetone cyclic diperoxide decomposes faster at all temperatures and revealed the occurrence of the enthalpy-entropy compensation effect for both peroxides. Probably those variations are due to substituents effects which in the present case derive from isotopic effects. Higher masses of deuterated substituents probably affect the stability of the tetraoxacyclohexane ring favoring the O-O bond rupture and the formation of the reaction products.

Also, an inverse kinetic secondary isotopic effect is observed $\left(\mathrm{k}_{\mathrm{H}} / \mathrm{k}_{\mathrm{D}}<1\right)$.

\section{ACKNOWLEDGEMENT}

This study was financially supported by the Comisión de Investigaciones Científicas de la provincia de Buenos Aires (CICPBA), Consejo Nacional de Investigaciones Científicas y Técnicas (CONICET) and the Secretaría de Ciencia, Arte y Tecnología de la Universidad Nacional del Centro de la Provincia de Buenos aires (SECAT, UNCPBA). K. Nesprias and G. Eyler are member of the CICPBA. G. Barreto is member of the CONICET. The authors acknowledge C. Coronel and L. Fernandez (University of Tucumán, Argentine) for providing compound dACDP.

\section{REFERENCES}

1. Mittleman, R.; Romig, L.; Gressmann, E.; J. Forensic Sci. 1986, 31, 312.

2. Cerna, J. R.; Morales, G.; Eyler, G. N.; Cañizo, A. I.; J. Appl. Polym. Sci. 2002, 83,1 .

3. Cañizo, A. I.; Eyler, G. N.; Mateo, C. M.; Alvarez, E. E.; Nesprias, R. K.; Heterocyles 2004, 63, 2231.

4. Dubnikova, F.; Kosloff, R.; Almog, J.; Zeiri, Y.; Boese, R.; Itzhaky, H.; Alt, A.; Keinan, E.; J. Am. Chem. Soc. 2005, 127, 1146.

5. Matyáš, R.; Šelešovský, J.; Musil, T.; Cent. Eur. J. Energ. Mater. 2013, 10, 263.

6. Yoshida, T.; Muranaga, K.; Matsunaga, T.; Tamura, M.; J. Hazard. Mater. 1985, 12, 27.

7. Cañizo, A. I.; Eyler, G. N.; Morales, G.; Cerna, J. R.; J. Phys. Org. Chem. 2004, 17, 215; $\quad$ Acuña, P.; Morales, G.; de León, R. D.; J. Appl. Polym. Sci. 2009, 114, 3198; Barreto, G.; Eyler, G.; Polym. Bull. 2011, 67, 1.

8. Cafferata, L. F. R.; Eyler, G. N.; Svartman, E. L.; Canizo, A. I.; Borkowski, E. J.; J. Org. Chem. 1990, 55, 1058.

9. Cafferata, L. F. R.; Eyler, G. N.; Svartman, E. L.; Canizo, A. I.; Alvarez, E.; J. Org. Chem. 1991, 56, 411.

10. Coronel, A. C.; Agüera, M. B.; Torres, A. C.; Fernández, L. E.; Varetti, E. L.; Vib. Spectrosc. 2012, 58, 67.

11. Nesprias, R.; Eyler, G.; Cañizo, A.; Aust. J. Chem. 2013, 66, 1080.

12. Cafferata, L. F. R.; Eyler, G. N.; Mirifico, M. V.; J. Org. Chem. 1984, 49, 2107.

13. Cañizo, A. I.; Cafferata, L.; An. Asoc. Quím. Argent. 1992, 80, 345.

14. Iglesias, M.; Barreto, G. P.; Eyler, G. N.; Cañizo, A. I.; Int. J. Chem. Kinet. 2010, 42, 347.

15. Eyler, G. N.; Mateo, C. M.; Alvarez, E. E.; Cañizo, A. I.; J. Org. Chem. 2000, 65, 2319.

16. Barreto, G. P.; Alvarez, E. E.; Eyler, G. N.; Cañizo, A. I.; Allegretti, P. E.; Aust. J. Chem. 2014, 67, 881.

17. Koenig, T. W.; Wolf, R.; J. Am. Chem. Soc. 1967, 89, 2948; Mead, P. T.; Donchi, K. F.; Traeger, J. C.; Christie, J. R.; Derrick, P. J.; J. Am. Chem. Soc. 1980, 102, 3364.

18. Tschuikow-Roux, E.; Niedzielski, J.; J. Photochem. 1984, 27, 141.

19. Williams, I. H.; J. Mol. Struct.: THEOCHEM 1983, 105, 105.

20. Youn, D. Y.; Hong, K. B.; Jung, K.-H.; Kim, D.; Kim, K.-R.; J. Chromatogr. A 1992, 607, 69.

21. Shanley, E. S.; J. Chem. Educ. 1990, 67, A41. 
22. Bali, M. S.; Armitt, D.; Wallace, L.; Day, A. I.; J. Forensic Sci. 2014, 59, 936.

23. Perrin, D. D.; Armarego, W. L. F.; Purification of laboratory chemicals, Pergamon Press: Oxford, 1988.

24. Huyberechts, M. S.; Halleux, A.; Kruys, P.; Bull. Soc. Chim. Belg. 1955, 64, 203.

25. Zhao, Y. H.; Abraham, M. H.; Zissimos, A. M.; J. Org. Chem. 2003, 68, 7368.
26. Cañizo, A. I.; Trends Org. Chem. 2006, 11, 55

27. Eyler, G. N.; Alvarez, E. E.; Minellono, C.; Cañizo, A. I.; Afinidad 2010, 67, 362.

28. Leiva, L. C. A.; Jorge, N. L.; Romero, J. M.; Cafferata, L. F. R.; Gómez Vara, M. E.; Castro, E. A.; J. Argent. Chem. Soc. 2008, 96, 111. 